\title{
Precipitation alters plastic film mulching impacts on soil respiration in an arid area of northwest China
}

\author{
Guanghui Ming ${ }^{1}$, Hongchang Hu ${ }^{1}$, Fuqiang Tian ${ }^{1}$, Zhenyang Peng ${ }^{1}$, Pengju Yang ${ }^{1}$, and Yiqi Luo ${ }^{2,3}$ \\ ${ }^{1}$ Department of Hydraulic Engineering, State Key Laboratory of Hydroscience and Engineering, \\ Tsinghua University, Beijing 100084, China \\ ${ }^{2}$ Department of Earth System Science, Tsinghua University, Beijing 100084, China \\ ${ }^{3}$ College of Engineering, Forestry, and Natural Sciences, Northern Arizona University, Flagstaff, Arizona, USA
}

Correspondence: Fuqiang Tian (tianfq@mail.tsinghua.edu.cn)

Received: 7 July 2017 - Discussion started: 11 August 2017

Revised: 21 April 2018 - Accepted: 10 May 2018 - Published: 30 May 2018

\begin{abstract}
Plastic film mulching (PFM) has widely been used around the world to save water and improve crop yield. However, the effect of PFM on soil respiration $\left(R_{\mathrm{S}}\right)$ remains unclear and could be further confounded by irrigation and precipitation. To address these topics, controlled experiments were conducted in mulched and non-mulched fields under drip irrigation from 2014 to 2016 in an arid area of the Xinjiang Uygur Autonomous Region, northwest China. The spatio-temporal pattern of soil surface $\mathrm{CO}_{2}$ flux as an index of soil respiration under drip irrigation with PFM was investigated, and the confounded effects of PFM and irrigation/precipitation on soil respiration were explored. The main findings were as follows. (1) Furrows, planting holes, and plastic mulch are three important pathways of soil $\mathrm{CO}_{2}$ emissions in mulched fields, of which the planting hole efflux outweighs that from the furrow, with the largest values of 8.0 and $6.6 \mu \mathrm{mol} \mathrm{m}^{-2} \mathrm{~s}^{-1}$, respectively, and the plastic mulch itself can emit up to $3.6 \mu \mathrm{mol} \mathrm{m} \mathrm{m}^{-2} \mathrm{~s}^{-1}$ of $\mathrm{CO}_{2}$. (2) The frequent application of water (i.e. through irrigation and precipitation) elevates soil moisture and soil respiration and enhances their variation. The resultant higher variation of soil moisture further alleviates the sensitivity of soil respiration to soil temperature, leading to a weak correlation and lower $Q_{10}$ values. (3) Soil $\mathrm{CO}_{2}$ effluxes from furrows and ridges in mulched fields outweigh the corresponding values in nonmulched fields in arid areas. However, this outweighing relation attenuates with increasing precipitation. Furthermore, by combining our results with those from the literature, we show that the difference in soil $\mathrm{CO}_{2}$ effluxes between nonmulched and mulched fields presents a linear relation with
\end{abstract}

the amount of precipitation, which results in negative values in arid areas and positive values in humid areas. Therefore, whether PFM increases soil respiration or not depends on the amount of precipitation during the crop-growing season.

\section{Introduction}

Soil respiration $\left(R_{\mathrm{S}}\right)$, the flux of microbe- and plant-respired $\mathrm{CO}_{2}$ from the soil surface to the atmosphere, represents the second largest $\mathrm{CO}_{2}$ flux of the terrestrial biosphere following gross primary productivity and amounts to 10 times the current rate of fossil-fuel combustion (Bond-Lamberty and Thomson, 2010; Davidson et al., 2006; L. Liu et al., 2016; Reichstein and Beer, 2008). Anthropogenic activities, particularly agriculture expansion and changes in cultivation practices, have brought significant challenges to the control of $\mathrm{CO}_{2}$ emissions in association with climate change (Baker et al., 2007). The conversion of natural to agricultural ecosystems has been recognized to cause a depletion of the soil organic carbon pool by as much as $60 \%$ (Lal, 2004), and soil respiration in agricultural ecosystems is relatively greater than that in natural ecosystems due to intensive cultivation (Buyanovsky et al., 1987; Raich and Tufekciogul, 2000).

A particular example is plastic film mulching (PFM), which was invented as an advanced agriculture cultivation technology for saving water and improving crop yield in the 1950s and has since been widely applied around the world, e.g. in the tropical USA, Europe, South Korea, and China. For instance, approximately $19 \%$ of the total arable land 
(130 million ha) in China was cultivated using PFM in 2014, while $0.85 \%$ of the arable land around the world was cultivated using this method (Y. P. Wang et al., 2016). Specifically, the PFM area has reached 1.2 million ha in the arid Xinjiang Uygur Autonomous Region, northwest China (Zhang et al., 2014). In a PFM field, this new method may alter the albedo, soil temperature, soil moisture, and crop growth conditions (Zhang et al., 2011), all of which can affect both heterotrophic and autotrophic respiration. Furthermore, the large-scale application of PFM may alter the regional climate, hydrologic cycle, and carbon cycle (Bonan, 2008; Li et al., 2016; Cox et al., 2000). Therefore, detecting the altered environmental conditions and $\mathrm{CO}_{2}$ emissions in PFM fields is crucial for the maintenance of regional and global soil carbon balances under the conditions of global climate change.

Only a few studies have addressed $\mathrm{CO}_{2}$ emissions in PFM fields, and they have provided contrasting results. For example, Yu et al. (2016) showed that the $\mathrm{CO}_{2}$ emissions from the soil surface in a mulched field in the southern Xinjiang Uygur Autonomous Region of China increased by $8 \%$ relative to a non-mulched field and that this increase mainly originates from furrows rather than ridges (please see Fig. 1 below for the configuration of furrows, ridges, planting holes, and mulch, etc.). However, $\mathrm{Li}$ et al. (2011) found that the $\mathrm{CO}_{2}$ concentrations in soil profiles are higher in mulched fields, but the soil $\mathrm{CO}_{2}$ efflux decreases by $21 \%$ relative to that in non-mulched fields in the northern Xinjiang Uygur Autonomous Region of China. Similar results showing that PFM decreased $\mathrm{CO}_{2}$ emissions were also found on the Loess Plateau of China (Xiang et al., 2014), in southwest China (Lei, 2016), and in a temperate monsoon climate area in Japan (Okuda et al., 2007). When investigating the emission pathways for greenhouse gases in the field, Berger et al. (2013) found that planting holes and furrows are important pathways for $\mathrm{N}_{2} \mathrm{O}$ emissions in mulched ridges. In addition, Nishimura et al. (2012) revealed in a laboratory experiment that $\mathrm{N}_{2} \mathrm{O}$ gradually permeates the plastic mulch. These findings indicate that the pathways for gas emissions in a mulched field may include furrows, planting holes, and plastic mulch, which have not been evaluated in terms of soil $\mathrm{CO}_{2}$ efflux in PFM fields. Some experimental studies have simply interpreted the soil respiration from furrows as the field averaged flux (Qian-Bing et al., 2012; Q. Liu et al., 2016), which may lead to the underestimation of soil respiration flux because ridges usually emit more $\mathrm{CO}_{2}$ than furrows.

In addition, irrigation and precipitation are also crucial to soil respiration due to the nature of the effects of moisture limitation on soil respiration in arid and semiarid regions, to which less attention has been paid. After irrigation and precipitation, soil moisture undergoes a wetting-drying cycle that affects soil porosity and influences the activities of root biomass and microorganisms, which control the soil carbon dynamics (Yan et al., 2014). Both the intensity and amount of irrigation/precipitation affect soil respiration. A small num- ber of studies have indicated that the soil respiration rate in a drip irrigation field is greater than that in a flood irrigation field (Guo et al., 2017; Qian-Bing et al., 2012). Plastic film mulching can modify the hydrological processes affected by precipitation or irrigation in different ways and may further impact soil respiration. For example, rainwater cannot infiltrate into ridges in a mulched field due to the barrier provided by plastic mulch, which, however, can cause an additional soil moisture increase in furrows. In contrast, the infiltration of irrigation water principally occurs in ridges under drip irrigation, as drip tapes are placed beneath the plastic mulch. The different impacts of PFM on the distribution of soil moisture caused by precipitation or irrigation may further have different influences on soil respiration. To the best of our knowledge, however, such different influences of PFM on soil respiration in terms of irrigation or precipitation have not yet been explored.

The main objective of this study was therefore to address the effect of PFM on soil respiration and the confounding influences of irrigation and precipitation. Controlled experiments under mulched and non-mulched drip irrigation conditions were conducted in a cotton field in the arid area of the Xinjiang Uygur Autonomous Region, northwest China. The soil respiration in different locations in mulched and nonmulched fields was continuously monitored in the growing seasons from 2014 to 2016. Based on the results from the experiment, we addressed the following questions. (1) What is the spatio-temporal pattern of soil respiration in a PFM field? (2) How does PFM affect soil respiration through its alteration of soil temperature and moisture? (3) What are the confounding effects of irrigation/precipitation and PFM on soil respiration?

\section{Study area and methods}

\subsection{Study area}

The experimental field site $\left(86^{\circ} 12^{\prime} \mathrm{E}, 41^{\circ} 36^{\prime} \mathrm{N} ; 886 \mathrm{~m}\right.$ above sea level) is located in one of the oases scattered on the alluvial plain of the Kaidu-Kongqi River (a tributary of the Tarim River) basin, north of the Taklamakan Desert in the Xinjiang Uygur Autonomous Region of northwest China. This region has a temperate continental climate, with a mean annual precipitation of $60 \mathrm{~mm}$, mean annual temperature of $11.48^{\circ} \mathrm{C}$, and mean annual water surface evaporation of $2788 \mathrm{~mm}$, as measured using a $20 \mathrm{~cm}$ diameter pan. The annual sunshine duration is $3036 \mathrm{~h}$, which is favourable for cotton (Gossypium hirsutum L.) growth. The experimental field covers an area of 3.48 ha. The major soil texture in the field is silt loam, the contents of the sand, silt and clay separately are $32.8,62.4$, and $4.8 \%$, respectively, and the soil bulk density ranges from 1.4 to $1.64 \mathrm{~g} \mathrm{~cm}^{-3}$ in the $1.5 \mathrm{~m}$ soil profile. The soil porosity is 0.42 , which was directly determined in the 
laboratory using undisturbed soil columns collected in the experimental field.

Cotton is usually sown in April and harvested during October and November; i.e. the growing season is from approximately DOY (day of the year) 100 to 300 . The planting style is "one film, one drip pipe beneath the film, and four rows of cotton above the film", as depicted in Fig. 1. The plastic film $(0.008 \mathrm{~mm}$ thick) was white and made of dense and airtight transparent polyethylene film. The width of the film was $1.1 \mathrm{~m}$, and the inter-film zone was $0.4 \mathrm{~m}$. Before sowing, small square holes $(2 \mathrm{~cm}$ length and width) were cut in the plastic film in rows at $0.1 \mathrm{~m}$ intervals for germination, seeds were placed in the holes, and each hole was covered with soil. The planting density was approximately 160000 plants ha $^{-1}$. The basic fertilizer that was applied annually before sowing included $173 \mathrm{~kg} \mathrm{ha}^{-1}$ of compound fertilizers $(14 \% \mathrm{~N}$, $16 \% \mathrm{P}_{2} \mathrm{O}_{5}$, and $\left.15 \% \mathrm{~K}_{2} \mathrm{O}\right), 518 \mathrm{~kg} \mathrm{ha}^{-1}$ of calcium superphosphate $\left(18 \% \mathrm{~N}\right.$ and $\left.40 \% \mathrm{P}_{2} \mathrm{O}_{5}\right)$, and $288 \mathrm{~kg} \mathrm{ha}^{-1}$ of diammonium phosphate $\left(\mathrm{P}_{2} \mathrm{O}_{5}>16 \%\right)$. Supplemental fertilizers applied during the growing season included approximately $292 \mathrm{~kg} \mathrm{ha}^{-1}$ of urea $(46 \% \mathrm{~N}), 586 \mathrm{~kg} \mathrm{ha}^{-1}$ of drip compound fertilizer $\left(13 \% \mathrm{~N}, 18 \% \mathrm{P}_{2} \mathrm{O}_{5}\right.$, and $\left.16 \% \mathrm{~K}_{2} \mathrm{O}\right)$, and foliar fertilizer $\left(\mathrm{P}_{2} \mathrm{O}_{5}>52 \%\right.$ and $\left.\mathrm{K}_{2} \mathrm{O}>34 \%\right)$. Drip irrigation usually began on 12 June in the bud stage, with an approximate amount of $20-50 \mathrm{~mm}$ during each application and 9-12 applications per growing season. The annual irrigation amount was 500-600 mm.

\subsection{Experimental set-up}

This study focuses on the growing season, as soil respiration in the non-growing season is extremely low. The mulched and non-mulched treatments were arranged in a randomized block design with three replicates in the same field with the same fertilization and irrigation scheme from the year 2014 to 2016. The plastic mulch had been covered until the seed germinated in the non-mulched treatment to protect the germinating seeds. The experiments began approximately before the bud stage, when the cotton began to grow faster. The dates of the beginning of the experiments were DOY 184, 175 , and 167 , and the lengths of the measured periods were 95,60 , and 100 days, respectively. Soil respiration measurements were carried out using an LI-8100A (LI-COR, Inc., Lincoln, Nebraska) on a day between two irrigation events. Therefore, soil respiration was measured approximately every week during the cotton-growing season. The automated soil $\mathrm{CO}_{2}$ flux measurement system consisted of two parts, PVC collars $(10 \mathrm{~cm}$ in diameter and $5 \mathrm{~cm}$ in height $)$ and a measuring chamber. The PVC collars were inserted $2-3 \mathrm{~cm}$ into the soil by removing the living plants and litter within the collars at least 1 day before the measurements. Data were recorded using the data logger in the LI-8100A system.

The soil respiration was measured in the following areas: the furrow and ridge in the non-mulched treatment and the furrow, planting hole, and plastic mulch in the mulched treat- ment in 2016 (see Fig. 1 for the experimental configuration). Soil respiration was measured in the furrow in the mulched treatment and in the ridge in the non-mulched treatment in 2014, and it was measured in the furrow in the mulched treatment and in both the furrow and ridge in the non-mulched treatment in 2015. The measurements were performed every $2 \mathrm{~h}$ during the experimental day from 08:00 to 24:00 UTC +8 . To measure the soil respiration at the soil surface without film covering (i.e. the furrows in the mulched and non-mulched fields and the non-mulched ridges), the PVC collars were inserted directly into the soil. Before measuring the $\mathrm{CO}_{2}$ emissions through the planting holes, the PVC collars were inserted into the soil covering two planting holes, and Scotch tape was used to seal the interspaces between the plastic mulch and collar to prevent air leakage. To measure the $\mathrm{CO}_{2}$ emissions through the plastic mulch, PVC collars were buried into the soil under the mulch, with Scotch Tape sealing the interspaces. Detailed measurement methods are further described in Berger et al. (2013). The soil temperature and soil moisture adjacent to each PVC collar at a depth of $5 \mathrm{~cm}$ were monitored using the auxiliary sensors of the LI$8100 \mathrm{~A}$ concurrently with the soil $\mathrm{CO}_{2}$ flux measurements. The amount of drip irrigation was determined using water meters installed on the branch pipes of the drip irrigation system. The precipitation was measured using a tipping bucket rain gauge (model TE525MM, Campbell Scientific Inc., Logan, UT, USA), which was mounted $0.7 \mathrm{~m}$ above the ground.

\subsection{Data analysis}

The soil respiration from different areas at a particular time of a day was calculated as the average of three replicates. The daily mean $R_{\mathrm{S}}$ was calculated as the average $R_{\mathrm{S}}$ measured at various times in a day. The $R_{\mathrm{S}}$ in the mulched ridges was calculated based on the area ratio of $R_{\mathrm{S}}$ measured through the planting holes and the plastic mulch:

$R_{\mathrm{r}-\mathrm{m}}=R_{\mathrm{h}-\mathrm{m}} \cdot A_{\mathrm{h}-\mathrm{m}}+R_{\mathrm{p}-\mathrm{m}} \cdot A_{\mathrm{p}-\mathrm{m}}$,

where $R_{\mathrm{h}-\mathrm{m}}$ and $R_{\mathrm{p}-\mathrm{m}}$ represent the soil respiration from the planting hole and plastic mulch, respectively, and constitute the soil respiration in the ridge $\left(R_{\mathrm{r}-\mathrm{m}}\right)$. The term $A$ represents the area ratio of the different parts, and $A_{\mathrm{h}-\mathrm{m}}$ and $A_{\mathrm{p}-\mathrm{m}}$ are 0.3 and 0.7 , respectively, in our field.

The seasonal accumulative $R_{\mathrm{S}}$ in the ridges and furrows was calculated by summing the $R_{\mathrm{S}}$ values over the measurement period (Yu et al., 2016; Berger et al., 2013). The soil respiration in plastic mulched and non-mulched fields was calculated based on the area ratio of $R_{\mathrm{S}}$ through ridges and furrows:

$$
\begin{aligned}
& R_{\mathrm{m}}=R_{\mathrm{r}-\mathrm{m}} \cdot A_{\mathrm{r}-\mathrm{m}}+R_{\mathrm{f}-\mathrm{m}} \cdot A_{\mathrm{f}-\mathrm{m}} \\
& R_{\mathrm{nm}}=R_{\mathrm{r}-\mathrm{nm}} \cdot A_{\mathrm{r}-\mathrm{m}}+R_{\mathrm{f}-\mathrm{nm}} \cdot A_{\mathrm{f}-\mathrm{m}},
\end{aligned}
$$

where $R_{\mathrm{m}}$ and $R_{\mathrm{nm}}$ represent soil respiration in mulched and non-mulched fields, respectively, and $A_{\mathrm{r}-\mathrm{m}}$ and $A_{\mathrm{f}-\mathrm{m}}$ are the 


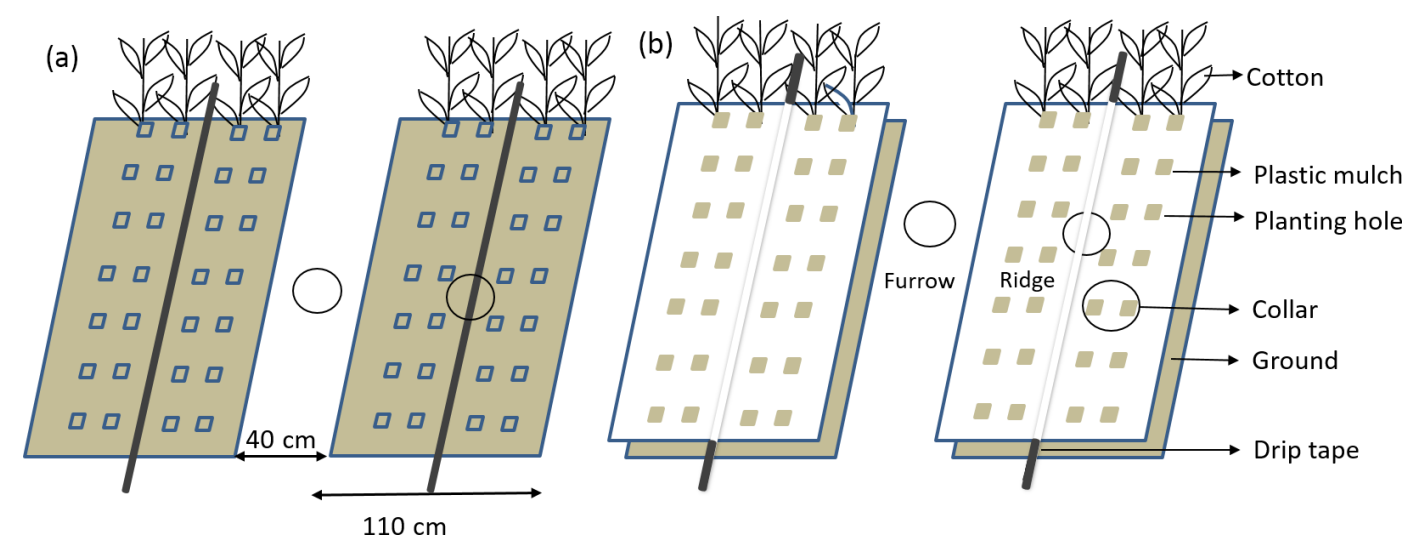

Figure 1. Schematic drawing of the experimental configuration for (a) a non-mulched field and (b) a mulched field.

area ratios of the ridge and furrow, respectively, which are the same for mulched and non-mulched fields and are 0.73 and 0.27 , respectively, in our field.

We used $t$ tests to test the significance of differences between the $R_{\mathrm{S}}$ values from the furrows and ridges of mulched and non-mulched fields.

The relationships between $R_{\mathrm{s}}$ and soil temperature and moisture were analysed using regression analysis in SPSS (Statistical Package for the Social Sciences) software. The van't Hoff equation was used to represent the relationship of $R_{\mathrm{S}}$ with soil temperature (van't Hoff, 1898):

$R_{\mathrm{S}}=A e^{b T}$,

where $R_{\mathrm{S}}$ represents the soil respiration, $T$ represents the soil temperature, and $A$ is the intercept of soil respiration when the soil temperature is $0^{\circ} \mathrm{C}$ (i.e. reference soil respiration). Moreover, $b$ represents the temperature sensitivity of soil respiration. The $Q_{10}$ value, which describes the change in soil respiration over a $10^{\circ}$ increase in soil temperature, is calculated as

$Q_{10}=e^{10 b}$.

Considering that low and high values of soil water content both limit soil respiration, we adopted a quadratic equation to simulate the effect of soil moisture on soil respiration according to Davidson et al. (1998):

$R_{\mathrm{S}}=a \mathrm{SWC}^{2}+b \mathrm{SWC}+c$,

where SWC is the soil water content, and $a, b$, and $c$ are regressed parameters.

\section{Results}

\subsection{Environmental factors and crop growth}

Figure 2 shows the dynamics of albedo, soil moisture, soil temperature, and cotton leaf area index (LAI), which sug- gest that these environmental factors and crop growth conditions are modified by PFM and other cultivation practices. Other than two snowfall events that occurred in January 2015 and January 2016 and elevated the albedo beyond 0.4, the albedo was altered by cultivation, as shown in Fig. 2b. In early March, it was increased by the spring irrigation conducted 1 month before sowing. Then, it was decreased by ploughing several days before mulching on approximately 20 April. After plastic mulching in April, the surface albedo showed a sudden rise and then slowly decreased with crop canopy development. In general, the albedo reached its minimum value along with the highest value of LAI during the bud stage in August and then increased very slowly with leaf fall.

The spatial distributions of soil moisture and soil temperature were both affected by plastic mulching. As shown in Fig. 2a, the soil moisture in ridges was mostly higher than that in furrows from the effect of frequent drip irrigation. Figure $2 \mathrm{c}$ shows that the soil temperature in the mulched ridge was higher than that in the open furrow. However, in the later growth stages, the soil temperature in the furrow became similar to or even exceeded that in the ridge due to canopy development.

Plastic film mulching can also affect plant phenology. As shown in Fig. 2d, the LAI began to increase with seed germination, reached its maximum value during the bud stage in August, and then decreased with leaf fall. The LAI in the mulched field was higher than that in the non-mulched field during the comparative experiment year of 2016, particularly in the vigorous growing stages.

\subsection{Seasonal and spatial variations in soil respiration}

As shown in Fig. 3, the magnitude and amplitude of $R_{\mathrm{S}}$ were rather different in different years. For example, the soil respiration fluxes in the non-mulched ridges were 1-6, 4-7, and $3-11 \mu \mathrm{mol} \mathrm{m}{ }^{-2} \mathrm{~s}^{-1}$, respectively, in the 3 years. The seasonal variation in $R_{\mathrm{S}}$ was generally mostly affected by soil temperature dynamics (this correlation will be further addressed in 

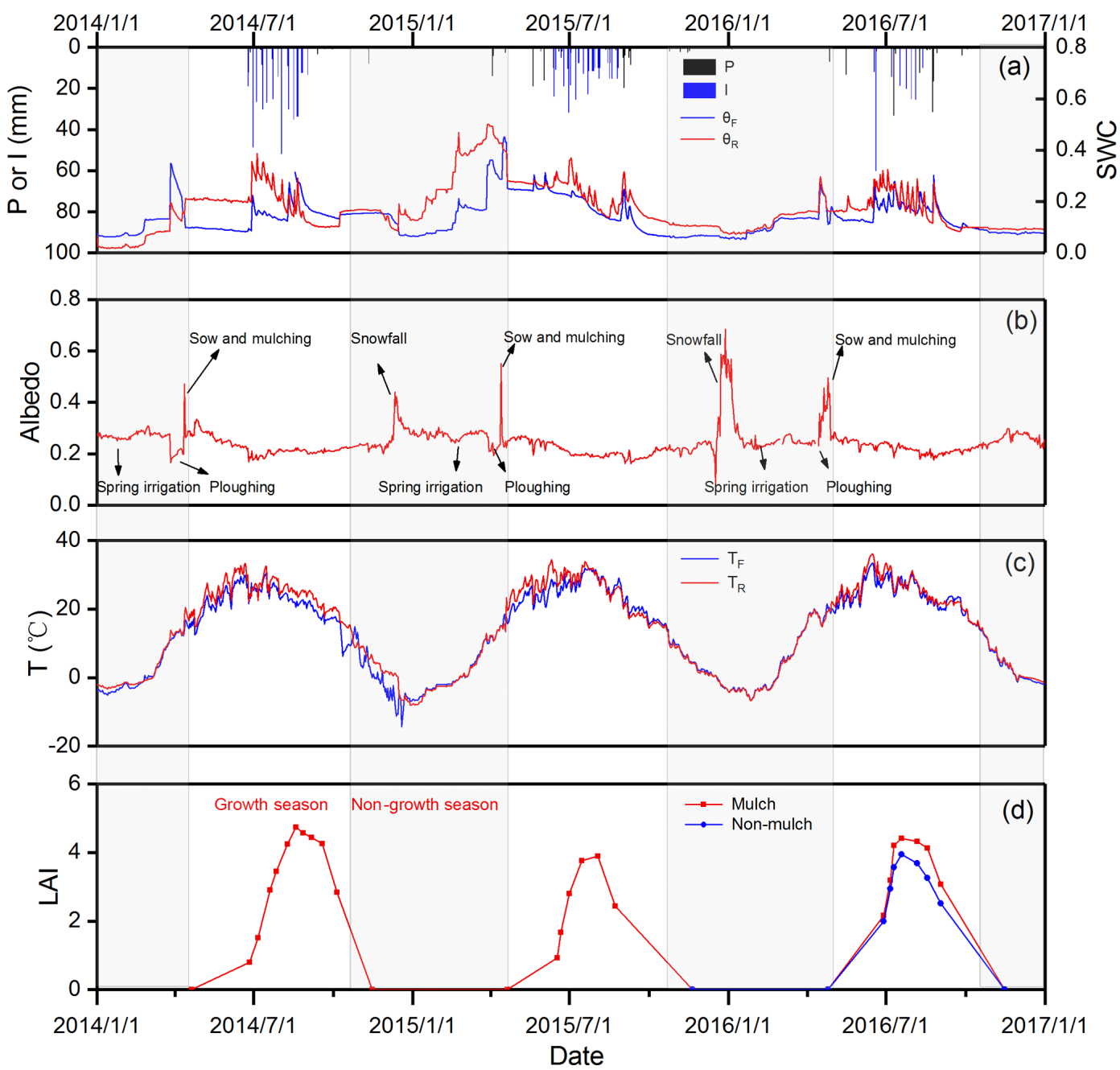

Figure 2. Environmental factors and crop growth in the PFM field under drip irrigation: (a) SWC in the ridge $\left(\theta_{\mathrm{R}}\right)$ and furrow $\left(\theta_{\mathrm{F}}\right)$ affected by irrigation and precipitation, (b) albedo affected by cultivation practices and snowfall in the mulched field, (c) $T$ (soil temperature) in the furrow $\left(T_{\mathrm{F}}\right)$ and ridge $\left(T_{\mathrm{R}}\right)$ in the mulched field, and (d) LAI in the mulched and non-mulched fields (comparative LAI measurements were only conducted in 2016). The shaded area indicates the non-growing season.

Sect. 3.4), although some anomalies occurred. For example, on DOY 180 in 2016, the $R_{\mathrm{S}}$ rates in the non-mulched ridge and planting hole reached peak values, while those in the furrows in both the mulched and non-mulched fields were fairly low. On the following DOY 192, however, the situation was reversed, and on DOY 235, all $R_{\mathrm{S}}$ fluxes experienced an abnormal declining and then rising cycle. These anomalies may be related to the SWC dynamics caused by irrigation and precipitation, which will be further explained in Sects. 3.5 and 3.6.

$R_{\mathrm{S}}$ showed significant spatial variability at the field scale. As shown in Fig. 3, the results in 2015 and 2016 indicated a consistently higher soil $\mathrm{CO}_{2}$ emission rate from the ridge than from the furrow in the non-mulched field. In the mulched field, as indicated by Fig. 3c, the $R_{\mathrm{S}}$ from the plastic film was very low, while the rate from the planting hole was higher than that from the furrow most of the time. For the
$R_{\mathrm{S}}$ from the furrow, its rate in the mulched field generally exceeded that in the non-mulched field in 2015 and 2016 except on DOY 222 in 2016, which occurred just after a $12.8 \mathrm{~mm}$ rainfall event, as shown in Fig. 8.

\subsection{Comparison of soil respiration in the mulched and non-mulched fields}

Figure 4 depicts the seasonal accumulative $R_{\mathrm{S}}$ and precipitation over the three experimental years. It should be noted that the $R_{\mathrm{S}}$ from the mulched ridge is the area-weighted summation of the terms from the plastic mulch and planting holes. A prominent feature of the figure is that the $R_{\mathrm{S}}$ fluxes over the ridge and furrow in the mulched field are consistently larger than the corresponding values in the nonmulched field. However, this magnitude relation was not significant in the furrow in 2015 and 2016 or in the ridge in 


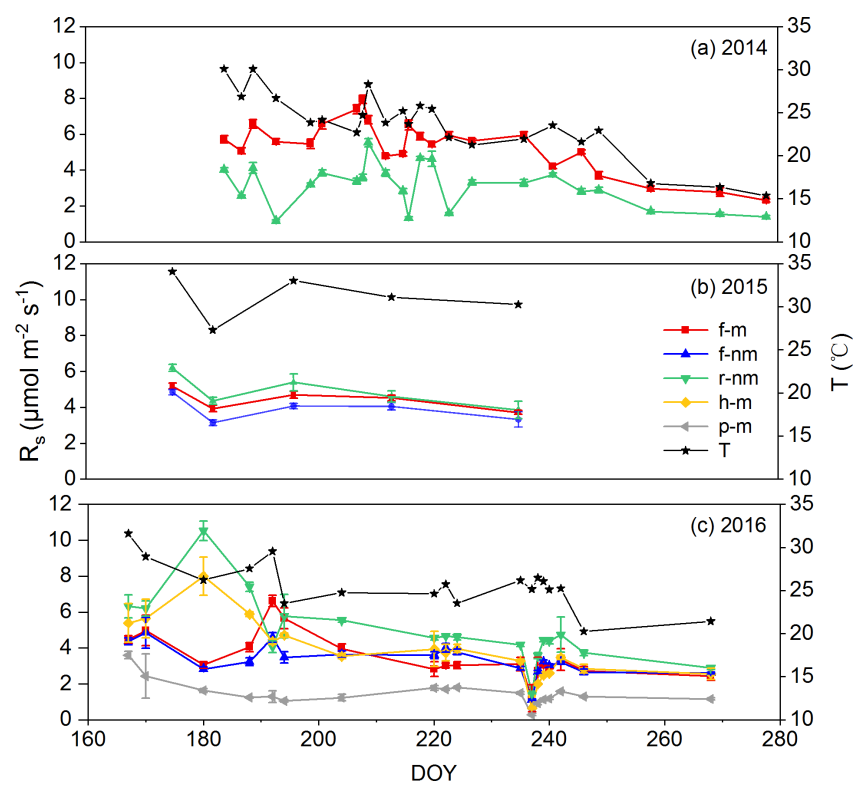

Figure 3. Spatio-temporal variation in soil respiration in mulched and non-mulched fields over the 3 years. The whiskers represent the standard deviation of three replicate $R_{\mathrm{S}}$ measurements (f-m, h$\mathrm{m}$, and $\mathrm{p}-\mathrm{m}$ represent furrow, planting hole, and plastic mulch in the mulched field, respectively; f-nm and r-nm represent the furrow and ridge in the non-mulched field, respectively; $T$ represents soil temperature).

2016 at a significance level of 0.05 (Table 1). Overall, the seasonal average $R_{\mathrm{S}}$ was $444.69 \mathrm{~g} \mathrm{C} \mathrm{m}^{-2}$ in the mulched field and $359.9 \mathrm{~g} \mathrm{C} \mathrm{m}^{-2}$ in the non-mulched field during the growing season over the 3 years. The accumulative $R_{\mathrm{S}}$ in the mulched field was indeed significantly larger than that in the non-mulched field in the years of 2014 and 2015. However, for the year of 2016, with a substantial precipitation amount of $130 \mathrm{~mm}$, the positive deviation of the mulched field $R_{\mathrm{S}}$ was not significant.

Additionally, the difference in the furrow $R_{\mathrm{S}}$ between the mulched and non-mulched field was smaller than the difference in the ridge over all the 3 years, and the magnitude of such differences decreased from 2014 to 2016. It should be noted that the seasonal precipitation presented an increasing trend from 2014 to 2016 . This indicates that more precipitation tends to eliminate the $R_{\mathrm{S}}$ differences between mulched and non-mulched fields.

\subsection{Functional relations between soil respiration and soil temperature}

All $R_{\mathrm{S}}$ fluxes in the different locations in the mulched and non-mulched fields showed increasing trends with temperature (Fig. 5), which were fitted using the exponential equation described in Sect. 2.3. However, their correlations are very weak and vary with location and time. The furrow possessed a higher $R^{2}$ than the ridge because of the relatively

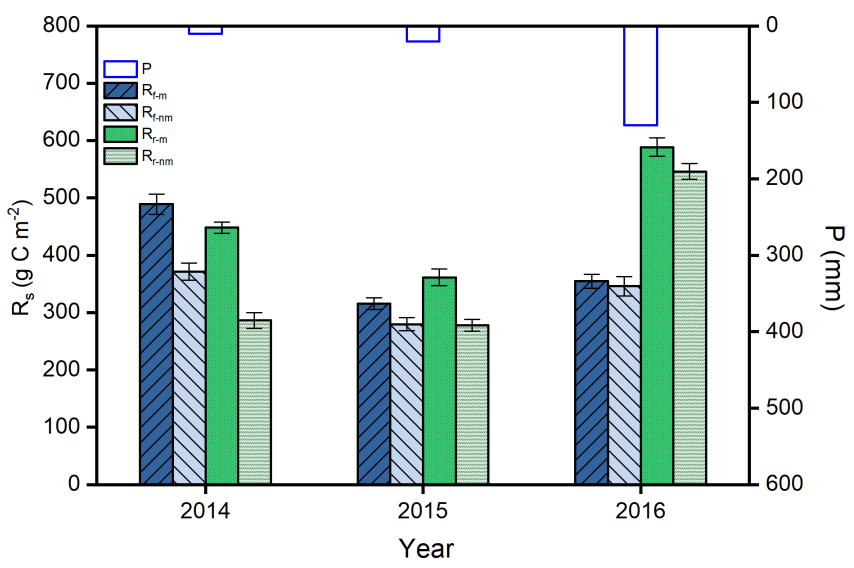

Figure 4. Seasonal accumulative soil respiration and precipitation over the three experimental years. The whiskers represent standard deviations ( $\mathrm{f}-\mathrm{m}$ and $\mathrm{r}-\mathrm{m}$ represent the furrow and ridge in the mulched field, respectively; f-nm and r-nm represent the furrow and ridge in the non-mulched field, respectively).

stable soil moisture in the furrow. Additionally, the $Q_{10}$ values in the furrows were much lower than those in the ridges.

\subsection{Irrigation and soil respiration}

The year 2014 was chosen to investigate the response of $R_{\mathrm{S}}$ to irrigation because of the very low number of precipitation events occurring in this year, and the results are shown in Fig. 6. It is clear that the soil moisture in the non-mulched ridge was always lower than that in the furrow in the mulched field except for some days immediately following irrigation. Relatively higher soil moisture favours soil respiration, and the $R_{\mathrm{S}}$ in the furrow in the mulched field was consequently always higher than that in the non-mulched ridge. Another dominant feature shown in Fig. 6 is the quick response of soil moisture and $R_{\mathrm{S}}$ to irrigation. The soil moisture experienced a quick increase after irrigation, while the $R_{\mathrm{S}}$ underwent a decline, which indicates that too much water in soil may restrain its respiration. Due to the configuration of the drip tape and plastic mulch, the soil moisture and respiration in the ridges of the mulched and non-mulched fields experienced similar but more drastic variations than those in the furrow.

To investigate the response of $R_{\mathrm{S}}$ to irrigation in more detail, the $R_{\mathrm{S}}$ dynamics across an irrigation cycle were explored. As $R_{\mathrm{S}}$ measurements were conducted on random dates between two irrigation events, data from different days after irrigation were collected to analyse the $R_{\mathrm{S}}$ variation. The effect of irrigation is presented by plotting $R_{\mathrm{S}}$ versus the number of days after irrigation during an irrigation cycle of approximately 6 days. The results in Fig. 7a show again that the $R_{\mathrm{S}}$ rate in the non-mulched ridge was extremely low immediately after irrigation and then slowly recovered, while irrigation had almost no influence on soil respiration in the 
Table 1. The $t$ test of significance was conducted for soil respiration in furrows and ridges and total soil respiration between mulched and non-mulched fields $\left(R_{\mathrm{m}}\right.$ and $R_{\mathrm{nm}}$ represent the total soil respiration in mulched and non-mulched fields, respectively. df represents the degrees of freedom, and $t_{0.05}(4)$ is the $t$ value at a significance value of 0.05 and a df of 4 ).

\begin{tabular}{rrrrrr}
\hline Year & $R_{\mathrm{f}-\mathrm{m}} / R_{\mathrm{f}-\mathrm{nm}}$ & $R_{\mathrm{r}-\mathrm{m}} / R_{\mathrm{r}-\mathrm{nm}}$ & $R_{\mathrm{m}} / R_{\mathrm{nm}}$ & df & $t_{0.05}(4)$ \\
\hline 2014 & 4.92 & 9.27 & 7.87 & 4 & 2.776 \\
2015 & 2.25 & 4.59 & 4.04 & & \\
2016 & 0.40 & 1.91 & 1.52 & & \\
\hline
\end{tabular}

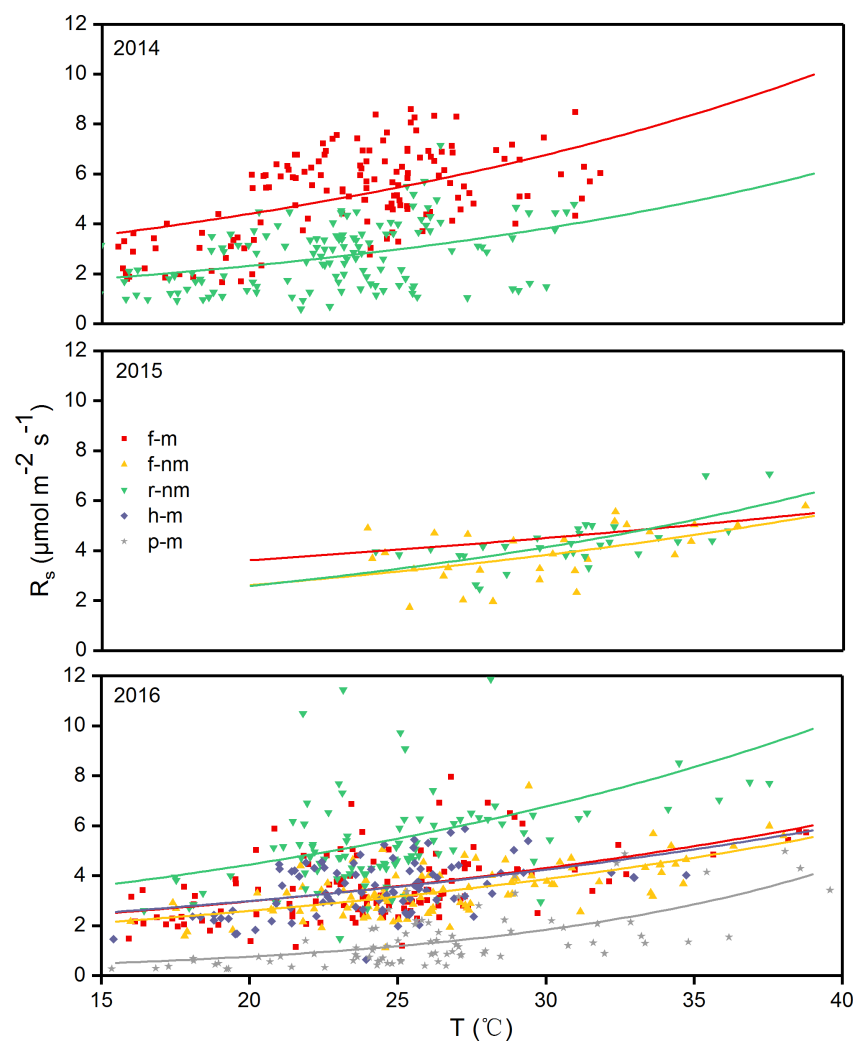

Figure 5. Relations between soil respiration and soil temperature at different locations in the mulched and non-mulched fields. The data represent the means \pm standard deviations (SDs) of three replicates. The regression lines for the different locations were fitted using Eq. (4), and the regression equations are shown in Table 2 (f-m, h-m, and $\mathrm{p}-\mathrm{m}$ represent furrow, planting hole, and plastic mulch, respectively; f-nm and r-nm represent furrow and ridge in non-mulched fields, respectively).

furrow of the mulched field. The $R_{\mathrm{s}}$ rates from both the furrow and ridge reached maximum values on the fourth day after irrigation and then began to decrease over the soil drying process. The relation between $R_{\mathrm{S}}$ and soil moisture can be expressed in the form of a binomial equation, as shown in Fig. $7 \mathrm{~b}$, which indicates that $R_{\mathrm{S}}$ is very low in dry soil and increases with soil moisture. However, $R_{\mathrm{s}}$ shows a declining trend when soil moisture exceeds a certain threshold. The threshold is approximately 0.25 in the furrow of
Table 2. Parameters for the fitted exponential equations relating soil respiration and soil temperature for different locations in the mulched and non-mulched fields (refer to Eqs. 4 and 5).

\begin{tabular}{lllllll}
\hline Year & Parameters & f-m & f-nm & r-nm & h-m & p-m \\
\hline \multirow{4}{*}{2014} & $a$ & 1.87 & & 0.86 & & \\
& $b$ & 0.04 & & 0.05 & & \\
& $Q_{10}$ & 1.54 & & 1.65 & & \\
& $R^{2}$ & 0.29 & & 0.18 & & \\
\hline \multirow{4}{*}{2015} & $a$ & 2.33 & 1.23 & 1.01 & & \\
& $b$ & 0.02 & 0.04 & 0.05 & & \\
& $Q_{10}$ & 1.25 & 1.46 & 1.60 & & \\
& $R^{2}$ & 0.18 & 0.27 & 0.43 & & \\
\hline \multirow{4}{*}{2016} & $a$ & 1.42 & 1.16 & 1.92 & 1.48 & 0.13 \\
& $b$ & 0.04 & 0.04 & 0.04 & 0.04 & 0.09 \\
& $Q_{10}$ & 1.45 & 1.49 & 1.52 & 1.42 & 2.41 \\
& $R^{2}$ & 0.23 & 0.39 & 0.20 & 0.18 & 0.44 \\
\hline
\end{tabular}

the mulched field and approximately 0.2 in the non-mulched ridge. The above thresholds are approximately 60 and $50 \%$ of the water-filled pore space, respectively.

\subsection{Precipitation and soil respiration}

The year 2016 was chosen to investigate the response of soil respiration to precipitation because a significant amount of rainfall occurred in this year. As shown in Fig. 8, $R_{\mathrm{S}}$ exhibited similar responses to irrigation in the planting hole and plastic mulch and non-mulched ridges, while it presented similar responses to precipitation in the furrows of mulched and non-mulched fields. In particular, three large rainfall events, with amounts of $12.8,36.8$, and $48 \mathrm{~mm}$, occurred on DOY 222, 192, and 235 in 2016, respectively. As we can see from Fig. 8, the light event (12.8 mm, DOY 222) had little effect on the soil moisture or $R_{\mathrm{s}}$, the moderate event $(36.8 \mathrm{~mm}$, DOY 192) restrained $R_{\mathrm{S}}$ in the non-mulched ridge and planting hole but increased $R_{\mathrm{S}}$ in the furrows of the mulched and non-mulched fields, and the heavy event (48 mm, DOY 235) restrained $R_{\mathrm{S}}$ in all parts of the mulched and non-mulched fields.

Using the heavy event as an example, the effect of precipitation on $R_{\mathrm{s}}$ during a wetting-drying cycle was more closely investigated before and after the event. As shown in Fig. 9, 


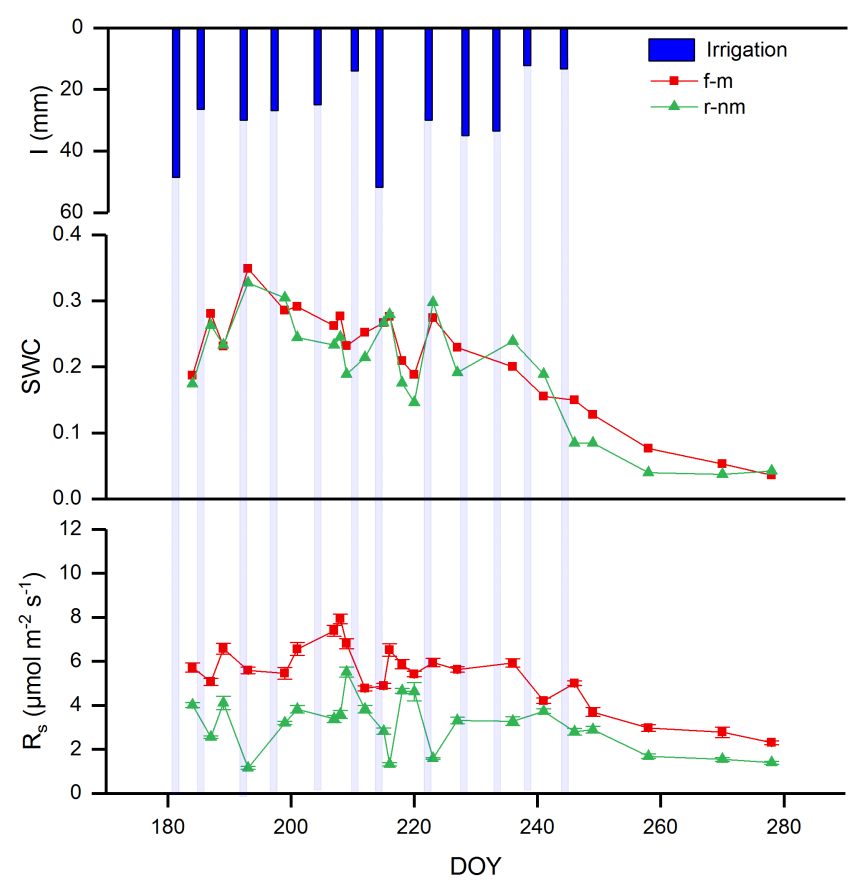

Figure 6. The responses of soil moisture and respiration to irrigation at different locations in the mulched and non-mulched fields in 2014 (f-m and r-nm represent the furrow in the mulched field and the ridge in the non-mulched field, respectively).

the $R_{\mathrm{S}}$ rates at all locations were restrained by substantially high soil water content. Then, the $R_{\mathrm{S}}$ recovered slowly with a decline in SWC and remained steady after 3 days.

\section{Discussion}

\subsection{Effect of plastic mulch on soil respiration}

Our experiment indicates that the planting hole emitted more $\mathrm{CO}_{2}$ than the furrow, with the largest values of 8.0 and $6.6 \mu \mathrm{mol} \mathrm{m}{ }^{-2} \mathrm{~s}^{-1}$, respectively, during the observation period (Fig. 3). In addition, the plastic mulch itself can also emit $\mathrm{CO}_{2}$ at a rate of $3.6 \mu \mathrm{mol} \mathrm{m}{ }^{-2} \mathrm{~s}^{-1}$. Considering that plastic mulch occupies most of the ridge area, it is also an important pathway of $\mathrm{CO}_{2}$ emissions in mulched fields. In fact, the soil $\mathrm{CO}_{2}$ emission rate of the plastic mulch depends on film features, including its thickness, texture, and colour. For example, according to Berger et al. (2013), thick black PE mulch releases extraordinarily low $\mathrm{N}_{2} \mathrm{O}$ emissions, while high amounts of $\mathrm{N}_{2} \mathrm{O}$ can be emitted from polyethylene film that is only $0.02 \mathrm{~mm}$ thick (Nishimura et al., 2012). Q. Liu et al. (2016) also reported that transparent plastic film emits more $\mathrm{CO}_{2}$ than black plastic mulch. Local farmers in our study area often use clear polyvinyl chloride (PVC) film with a thickness of only $0.008 \mathrm{~mm}$ because of its low price. This film has a relatively high diffusion capacity for $\mathrm{CO}_{2}$, as indicated by our results. Additionally, thin and low-density plas-
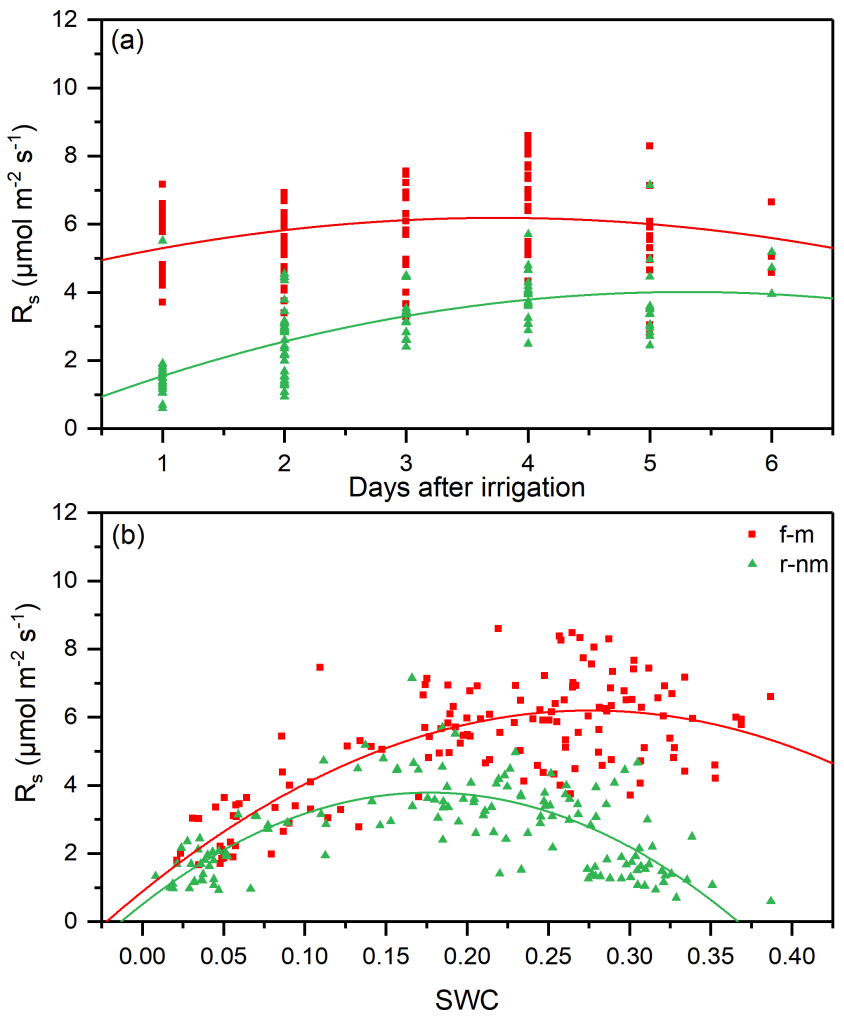

Figure 7. Influence of irrigation on soil respiration. (a) Variation in soil respiration with number of days after irrigation. (b) Relation between soil respiration and soil moisture (regression lines are fitted with the binomial equation in Eq. (6) (f-m and $\mathrm{r}-\mathrm{nm}$ represent the furrow in the mulched field and the ridge in the non-mulched field, respectively).

tic film is easily damaged, resulting in plastic film residue, which can affect crop germination, water absorption, nutrition, and yield. Plastic film residue can also inhibit soil microbial activity, which reduces soil fertility, causing substantive costs to the environment and farmers (J. Wang et al., 2016; Adhikari et al., 2016). High-density plastic film is therefore recommended for the purpose of reducing soil $\mathrm{CO}_{2}$ emissions and plastic film residues despite its higher price. In general, the planting hole, furrow, and plastic mulch are primary pathways that are responsible for $\mathrm{CO}_{2}$ emissions in a mulched field. A comprehensive measurement scheme including different locations is therefore necessary to assess $R_{\mathrm{S}}$ in a mulched field. Our results can potentially be used to correct the reported $\mathrm{CO}_{2}$ emissions measured only at the furrow in a mulched field (Qian-Bing et al., 2012; Q. Liu et al., 2016).

Our experiment also showed higher soil $\mathrm{CO}_{2}$ emission rates from furrows and ridges in the mulched field compared to the corresponding locations in the non-mulched field. Therefore, PFM can indeed promote soil respiration in our study area. This is principally due to improved soil temperature, soil moisture, and crop growth as a result of plas- 

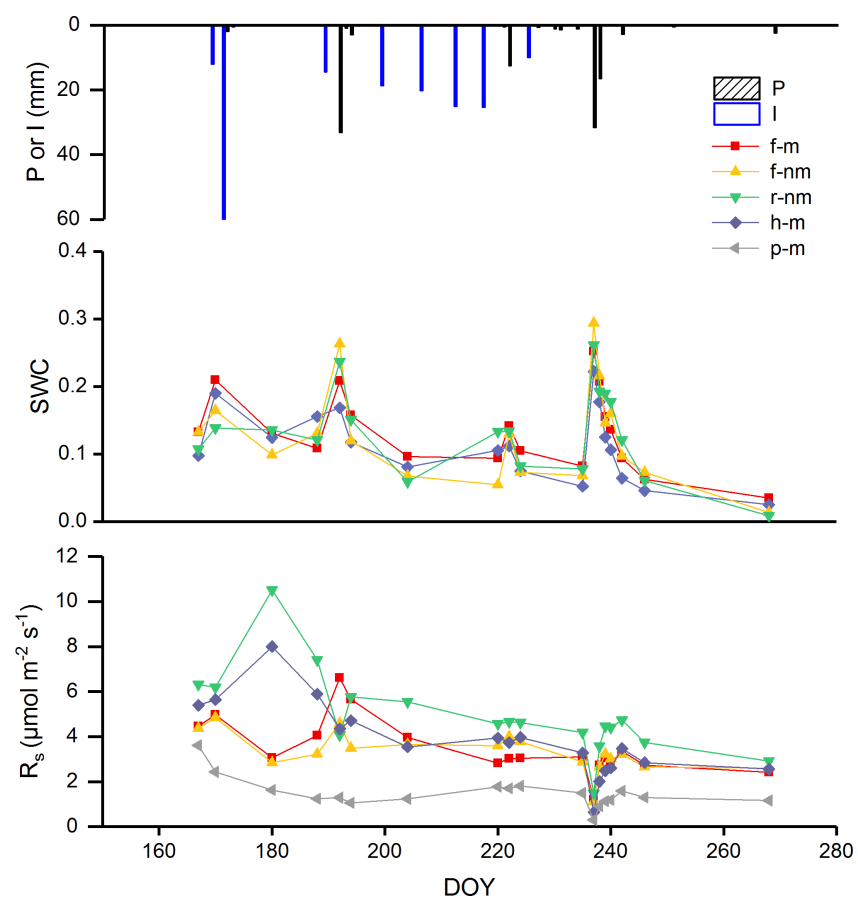

Figure 8. Response of soil moisture and soil respiration to precipitation and irrigation during 2016 (f-m, h-m and p-m represent the furrow, planting hole, and plastic mulch in the mulched field, respectively; f-nm and $\mathrm{r}-\mathrm{nm}$ represent the furrow and ridge in the non-mulched field, respectively).

tic mulching (see Fig. 2). Improved crop growth conditions result in the production of more root biomass and litter fall, which will promote root respiration and litter fall decomposition. Moreover, improved soil temperature and soil moisture can promote the activities of roots and microorganisms to increase the mineralization of soil organic carbon, for example, by stimulating the decomposition of buried crop straw (Y. P. Wang et al., 2016). This result was partly confirmed by Yu et al. (2016), who reported that furrow $R_{\mathrm{S}}$ in the mulched field is greater than that in the non-mulched field. However, they also reported that the $R_{\mathrm{S}}$ rates from mulched and non-mulched ridges are similar, which differs from our results. Furthermore, some other studies found contrasting results (i.e. PFM decreases $R_{\mathrm{S}}$ ) in the northern Xinjiang Uygur Autonomous Region of China (Li et al., 2011), the Loess Plateau of China (Xiang et al., 2014), southwest China (Lei, 2016), and central Japan (Okuda et al., 2007). Additionally, Berger et al. (2013) found that PFM significantly decreases $\mathrm{N}_{2} \mathrm{O}$ emissions in South Korea. Therefore, the effects of plastic mulch on $R_{\mathrm{S}}$ differ in different areas. Our work reveals that the difference in $R_{\mathrm{S}}$ between mulched and non-mulched fields depends on the precipitation amount. This could be the reason leading to the contradictory results, which will be discussed in more detail in the following section.
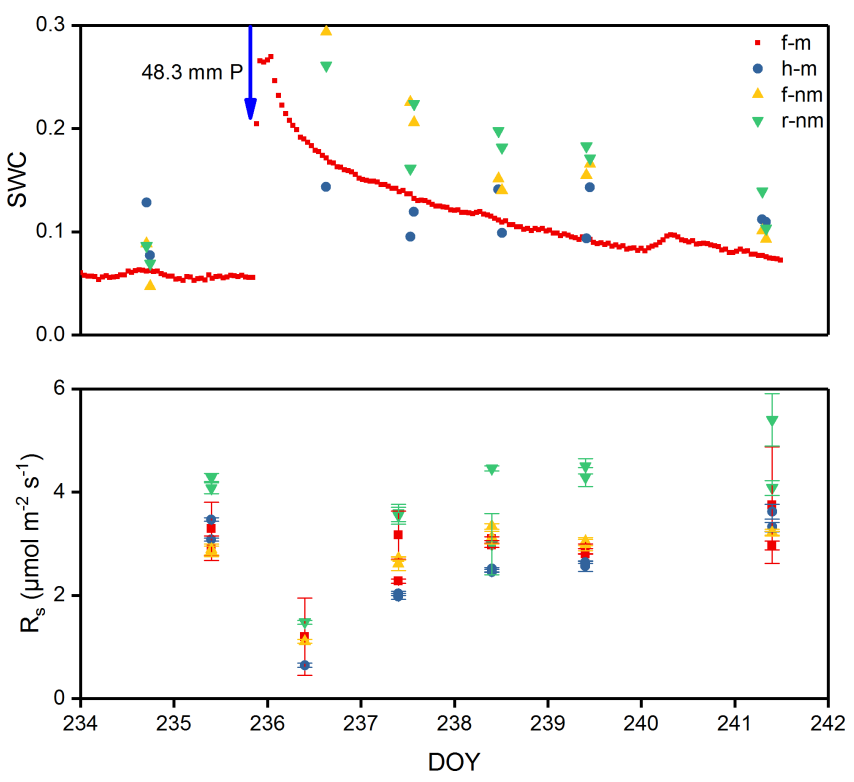

Figure 9. Variations in soil moisture and soil respiration during a wetting-drying cycle after a heavy rainfall.

\subsection{Effects of irrigation and precipitation on soil respiration}

Our results indicate that the substantially high SWC occurring right after irrigation and precipitation restrained $R_{\mathrm{s}}$, and this effect decreased as the soil moisture returned to the normal level (Figs. 7a and 9). In contrast, in natural ecosystems, precipitation always immediately increases $R_{\mathrm{s}}$, similar to water addition after a long drought in a tallgrass prairie ecosystem in Oklahoma, USA (Liu et al., 2002), and $12 \mathrm{~mm}$ of precipitation in an oak/grass savanna ecosystem in California (Xu and Baldocchi, 2004). This is due to the so-called soil degassing effect, which is the non-steady-state $\mathrm{CO}_{2}$ efflux at the soil surface occurring mostly during rainfall or irrigation after long periods of drought (Luo and Zhou, 2006). In agricultural systems, however, frequent irrigation occurs to satisfy crop water requirements and maintains favourable soil moisture. This further renders higher $R_{\mathrm{S}}$ than in natural ecosystems, particularly in arid areas. Our results further indicate that SWC that is either too low or too high can restrain $R_{\mathrm{S}}$, which can be expressed by a quadratic equation (Fig. 7b). The quadratic (parabolic) relationship between SWC and $R_{\mathrm{S}}$ has also been detected in maize fields, a tallgrass prairie, and oak/grass savannah ecosystems (Yinkun et al., 2013; Xu et al., 2004; Liu et al., 2002; Mielnick and Dugas, 2000). This is because that lower water content affects the diffusion of soluble substrates, while higher water content affects the diffusion and availability of oxygen (Davidson et al., 2006; Linn and Doran, 1984). Our results confirm findings by Wang et al. (2010), who reported that irrigation stimulates $R_{\mathrm{S}}$ but that too much water reduces it, especially shortly after irrigation (Wang et al., 2010). In addition to our quadratic functional 
relation between SWC and $R_{\mathrm{S}}$, the effect of SWC on $R_{\mathrm{S}}$ has also been described by linear, logarithmic, or parabolic functions in different ecosystems around the world (Davidson et al., 2000). For example, in a mountain oasis in Oman, soil respiration has been described to be linearly correlated with the SWC (Wichern et al., 2004). To be noted, the range of SWC in Wichern et al. (2004) is from 0.14 to 0.25 , which is lower than the soil moisture threshold necessary to restrain $R_{\mathrm{S}}$ found in our study; therefore, the authors did not find a parabolic correlation like we did. More theoretical efforts should be made to reconcile these different experimental results and obtain a general relationship between SWC and $R_{\mathrm{S}}$.

Our results indicate that the correlations between $R_{\mathrm{S}}$ and temperature and the temperature sensitivity (i.e. $Q_{10}$ ) are rather low in our PFM field equipped with drip irrigation (Table 2). The obtained $R^{2}$ values of $0.18-0.44$ are much lower than the reported values from natural ecosystems, such as in a tall grass prairie in central Oklahoma, USA, with an $R^{2}$ of 0.77-0.97 (Luo et al., 2001), and in the Harvard Forest in central Massachusetts, USA, with an $R^{2}$ of 0.8 (Davidson et al., 1998). The obtained $Q_{10}$ values of 1.25-1.65 (Table 2, except for in the planting hole) are below the median of 2.4 reported in a literature review of global soil respiration (Raich and Schlesinger, 1992). Additionally, they are much smaller than the $Q_{10}$ of 3.8 found in rain-fed maize cropland on the Loess Plateau of China (Xiang et al., 2012). In contrast, relatively higher correlations between $R_{\mathrm{S}}$ and SWC indicate that the SWC may be the main factor affecting $R_{\mathrm{S}}$ in a PFM field under drip irrigation. Lower $Q_{10}$ values indicate that the sensitivity of $R_{\mathrm{S}}$ to temperature has been weakened by higher variation in the soil moisture induced by irrigation and precipitation.

Our results clearly reveal the confounding influence of PFM and precipitation on soil respiration. The hydrological responses to precipitation in the field were changed by the impermeable plastic mulch, which is the reason that the effect of precipitation on $R_{\mathrm{S}}$ differed in the mulched and nonmulched fields. For example, the $R_{\mathrm{S}}$ rate in the non-mulched ridge was higher than that in the furrow of mulched fields and planting hole during 2016, in which high precipitation occurred. However, this result contrasted with the results from 2014 and 2015, during which less rainfall occurred. Additionally, although the soil respiration rate in the mulched field was always higher than that in the non-mulched field during all 3 years, the significance of this magnitude relation decreased with increasing precipitation. Therefore, we can speculate that the magnitude at which the mulch accelerates soil respiration should be related to the amount of precipitation.

To verify the above assertion, a meta-analysis was carried out. The relationship between the amount of annual precipitation $(P)$ and the differences in the annual $R_{\mathrm{S}}$ (denoted as df, i.e. $R_{\mathrm{S}}$ in the non-mulched field minus that in the mulched field) was analysed (Fig. 10). The relevant studies include studies conducted in an arid area $(P=45.7 \mathrm{~mm})$ in south-

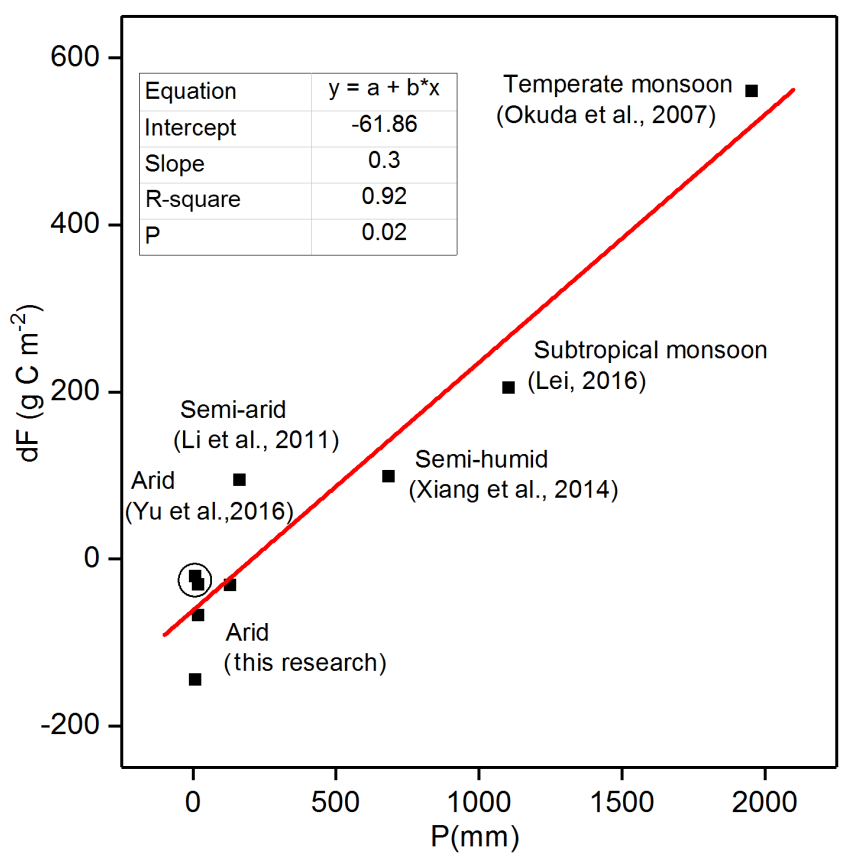

Figure 10. The relationship of the difference in soil respiration between the mulched and non-mulched fields with precipitation; df represents the soil respiration in the non-mulched field minus that in the mulched field. Among the five points representing arid areas, the data from Yu et al. (2016) are within the circle, while those from our study are outside of the circle.

ern Xinjiang (Yu et al., 2016), a semiarid area $(P=160 \mathrm{~mm})$ in northern Xinjiang (Li et al., 2011), a semi-humid area $(P=566.8 \mathrm{~mm})$ on the Loess Plateau of China (Xiang et al., 2014), a subtropical monsoon area $(P=1105 \mathrm{~mm})$ in southwest China (Lei, 2016), and a temperate monsoon climate area $(P=1954 \mathrm{~mm})$ in Japan (Okuda et al., 2007). The df was found to have a linear relationship with the amount of precipitation. Under the condition of $200 \mathrm{~mm}$ of annual precipitation, the $R_{\mathrm{S}}$ rates in the mulched and non-mulched fields are roughly identical. When the annual precipitation was greater than $200 \mathrm{~mm}$, the $R_{\mathrm{S}}$ was lower in the mulched field than in the non-mulched field. This is the reason why the results of some studies contrasted with our results showing that PFM decreases $R_{\mathrm{s}}$.

Based on the relationships between precipitation and soil respiration in the PFM fields obtained above, plastic film mulching is recommended for application in areas with precipitation greater than $200 \mathrm{~mm}$, i.e. semi-arid and humid areas, to decrease soil $\mathrm{CO}_{2}$ emissions and increase soil carbon sequestration. Decreasing soil $\mathrm{CO}_{2}$ emissions indicates increasing soil organic carbon and maintenance of soil fertility to obtain a stable yield. Our results are consistent with those of Zhang et al. (2018), who concluded that PFM where precipitation is greater than $230 \mathrm{~mm}$ can result in a stable crop yield on the Loess Plateau. 


\section{Summary}

Plastic film mulching is now widely used in agriculture around the world due to the continuous fall in the prices of plastic products, particularly in developing countries, such as China. The changing land cover with great numbers of PFM fields and the changing climate will affect the energy, water, and carbon cycles regionally and globally. From the comprehensive analysis and discussion of the effects of plastic mulch, irrigation, and precipitation on soil respiration based on the results of our controlled experiment, some new findings were discovered in this study. First, PFM can enhance the spatial heterogeneity of soil respiration under drip irrigation, and planting holes, furrows, and plastic mulch (ordered by emission rate) are three important pathways of surface soil $\mathrm{CO}_{2}$ emissions. Second, PFM can increase soil respiration at the field scale in arid areas, while this enhancement depends on the amount of precipitation. A linear relationship was found between the difference in soil respiration (between non-mulched and mulched fields) and the amount of precipitation at the annual scale. Plastic film mulching is therefore beneficial for carbon sequestration in wet areas, while it is harmful in arid areas. Third, the frequent application of water elevates soil moisture and soil respiration and enhances their variation. The resultant higher variation in soil moisture further alleviates the sensitivity of soil respiration to soil temperature, leading to a weak correlation and low $Q_{10}$ values.

Our results suggest that the rapid expansion of PFM fields in arid areas brings new challenges for controlling greenhouse gas emissions. Plastic film mulching and irrigation should be better integrated into future soil carbon models. Linking the hydrologic and carbon cycles via the conservation of water resources is crucial for improving agronomic yields and soil carbon sequestration in dry lands.

Data availability. In order to access the data, we kindly ask researchers to contact the corresponding author.

Competing interests. The authors declare that they have no conflict of interest.

Acknowledgements. This research was support by the National Key Research and Development Program of China (2016YFC0402701, 2016YFA0601603), the National Science Foundation of China (NSFC 91647205), and the Foundation of the State Key Laboratory of Hydroscience and Engineering of Tsinghua University (2016KY-03). We gratefully appreciate their support. We acknowledge the staff at Tsinghua University Oasis Eco-Hydrology Experimental Research Station for their kind help and assistance. Additionally, the authors thank Mohd Yawar Ali Khan for help with language improvement.
Edited by: Nandita Basu

Reviewed by: two anonymous referees

\section{References}

Adhikari, R., Bristow, K. L., Casey, P. S., Freischmidt, G., Hornbuckle, J. W., and Adhikari, B.: Preformed and sprayable polymeric mulch film to improve agricultural water use efficiency, Agric. Water Manage., 169, 1-13, https://doi.org/10.1016/j.agwat.2016.02.006, 2016.

Baker, J. M., Ochsner, T. E., Venterea, R. T., and Griffis, T. J.: Tillage and soil carbon sequestration - What do we really know?, Agric. Ecosyst. Environ., 118, 1-5, 2007.

Berger, S., Kim, Y., Kettering, J., and Gebauer, G.: Plastic mulching in agriculture - Friend or foe of $\mathrm{N}_{2} \mathrm{O}$ emissions?, Agric. Ecosyst. Environ., 167, 43-51, https://doi.org/10.1016/j.agee.2013.01.010, 2013.

Bonan, G.: Ecological climatology, Cambridge University Press, Cambridge, 352-359, 2008.

Bond-Lamberty, B. and Thomson, A.: A global database of soil respiration data, Biogeosciences, 7, 1915-1926, https://doi.org/10.5194/bg-7-1915-2010, 2010.

Buyanovsky, G. A., Kucera, C. L., and Wagner, G. H.: Comparative Analyses of Carbon Dynamics in Native and Cultivated Ecosystems, Ecology, 68, 2023-2031, https://doi.org/10.2307/1939893, 1987.

Cox, P. M., Betts, R. A., Jones, C. D., Spall, S. A., and Totterdell, I. J.: Acceleration of global warming due to carbon-cycle feedbacks in a coupled climate model, Nature, 408, 184-187, 2000.

Davidson, E. A., Belk, E., and Boone, R. D.: Soil water content and temperature as independent or confounded factors controlling soil respiration in a temperate mixed hardwood forest, Global Change Biol., 4, 217-227, https://doi.org/10.1046/j.13652486.1998.00128.x, 1998.

Davidson, E. A., Verchot, L. V., Catt, X., Nio, J. H., Ackerman, I. L., and Carvalho, J. E. M.: Effects of Soil Water Content on Soil Respiration in Forests and Cattle Pastures of Eastern Amazonia, Biogeochemistry, 48, 53-69, 2000.

Davidson, E. A., Janssens, I. A., and Luo, Y.: On the variability of respiration in terrestrial ecosystems: moving beyond $Q_{10}$, Global Change Biol., 12, 154-164, https://doi.org/10.1111/j.13652486.2005.01065.x, 2006.

Guo, S., Qi, Y., Peng, Q., Dong, Y., He, Y., Yan, Z., and Wang, L.: Influences of drip and flood irrigation on soil carbon dioxide emission and soil carbon sequestration of maize cropland in the North China Plain, J. Arid Land, 9, 222-233, https://doi.org/10.1007/s40333-017-0011-9, 2017.

Lal, R.: Soil Carbon Sequestration Impacts on Global Climate Change and Food Security, Science, 304, 1623-1627, https://doi.org/10.1126/science.1097396, 2004.

Lei, L.: Study of effect of plastic film mulching on $\mathrm{CO}_{2}$ and $\mathrm{CH}_{4}$ emissions from a vegetable field, Master of Environmental Engineering, Southwest University, Chongqing, China, 59 pp., 2016.

Li, N., Tian, F., Hu, H., Lu, H., and Ming, G.: Effects of Plastic Mulch on Soil Heat Flux and Energy Balance in a Cotton Field in Northwest China, Atmosphere, 7, 1-16, 2016.

Li, Z.-G., Zhang, R.-H., Wang, X.-J., Wang, J.-P., Zhang, C.P., and Tian, C.-Y.: Carbon Dioxide Fluxes and Concentra- 
tions in a Cotton Field in Northwestern China: Effects of Plastic Mulching and Drip Irrigation, Pedosphere, 21, 178-185, https://doi.org/10.1016/s1002-0160(11)60116-1, 2011.

Linn, D. M. and Doran, J. W.: Effect of Water-Filled Pore Space on Carbon Dioxide and Nitrous Oxide Production in Tilled and Nontilled Soils1, Soil Sci. Soc. Am. J., 48, 1267-1272, https://doi.org/10.2136/sssaj1984.03615995004800060013x, 1984.

Liu, L., Wang, X., Lajeunesse, M. J., Miao, G., Piao, S., Wan, S., Wu, Y., Wang, Z., Yang, S., Li, P., and Deng, M.: A crossbiome synthesis of soil respiration and its determinants under simulated precipitation changes, Global Change Biol., 22, 13941405, https://doi.org/10.1111/gcb.13156, 2016.

Liu, Q., Chen, Y., Li, W., Liu, Y., Han, J., Wen, X., and Liao, Y.: Plastic-film mulching and urea types affect soil $\mathrm{CO}_{2}$ emissions and grain yield in spring maize on the Loess Plateau, China, Sci. Rep., 6, 28150, https://doi.org/10.1038/srep28150, 2016.

Liu, X., Wan, S., Su, B., Hui, D., and Luo, Y.: Response of soil $\mathrm{CO}_{2}$ efflux to water manipulation in a tallgrass prairie ecosystem, Plant Soil, 240, 213-223, https://doi.org/10.1023/a:1015744126533, 2002.

Luo, Y. and Zhou, X. (Eds.): Soil respiration and the environment, Elsevier, New York, 35-40, 2006.

Luo, Y., Wan, S., Hui, D., and Wallace, L. L.: Acclimatization of soil respiration to warming in a tall grass prairie, Nature, 413, 622-625, 2001.

Mielnick, P. C. and Dugas, W. A.: Soil CO2 flux in a tallgrass prairie, Soil Biol. Biochem., 32, 221-228, https://doi.org/10.1016/S0038-0717(99)00150-9, 2000.

Nishimura, S., Komada, M., Takebe, M., Yonemura, S., and Kato, N.: Nitrous oxide evolved from soil covered with plastic mulch film in horticultural field, Biol. Fertil. Soils, 48, 787-795, https://doi.org/10.1007/s00374-012-0672-7, 2012.

Okuda, H., Noda, K., Sawamoto, T., Tsuruta, H., Hirabayashi, T., Yonemoto, J. Y., and Yagi, K.: Emission of $\mathrm{N}_{2} \mathrm{O}$ and $\mathrm{CO}_{2}$ and Uptake of CH4 in Soil from a Satsuma Mandarin Orchard under Mulching Cultivation in Central Japan, J. Jpn. Soc. Hort. Sci., 76, 279-287, https://doi.org/10.2503/jjshs.76.279, 2007.

Qian-Bing, Z., Ling, Y., Jin, W., Hong-Hai, L., Ya-Li, Z., and WangFeng, Z.: Effects of Different Irrigation Methods and Fertilization Measures - on Soil Respiration and Its Component Contrib, Sci. Agricult. Sin., 45, 2420-2430, 2012.

Raich, J. W. and Schlesinger, W. H.: The global carbon dioxide flux in soil respiration and its relationship to vegetation and climate, Tellus B, 44, 81-99, https://doi.org/10.1034/j.16000889.1992.t01-1-00001.x, 1992.

Raich, J. W. and Tufekciogul, A.: Vegetation and soil respiration: Correlations and controls, Biogeochemistry, 48, 71-90, https://doi.org/10.1023/a:1006112000616, 2000.

Reichstein, M. and Beer, C.: Soil respiration across scales: The importance of a model-data integration framework for data interpretation, J. Plant Nutr. Soil Sci., 171, 344-354, https://doi.org/10.1002/jpln.200700075, 2008.

van't Hoff, J.: Lectures on Theoretical and Physical Chemistry. Part 1. Chemical Dynamics, Edward Arnold, London, 224-226, 1898.
Wang, J., Fenghua, Z., and Zhu, O.: Effects of irrigation quantity on soil respiration in wheat field in filling stage, Agricult. BorealiSim., 25, 186-189, 2010.

Wang, J., Lv, S., Zhang, M., Chen, G., Zhu, T., Zhang, S., Teng, Y., Christie, P., and Luo, Y.: Effects of plastic film residues on occurrence of phthalates and microbial activity in soils, Chemosphere, 151, 171-177, https://doi.org/10.1016/j.chemosphere.2016.02.076, 2016.

Wang, Y. P., Li, X. G., Fu, T., Wang, L., Turner, N. C., Siddique, K. H. M., and Li, F.-M.: Multi-site assessment of the effects of plastic-film mulch on the soil organic carbon balance in semiarid areas of China, Agric. For. Meteorol., 228-229, 42-51, 2016.

Wichern, F., Luedeling, E., Müller, T., Joergensen, R. G., and Buerkert, A.: Field measurements of the $\mathrm{CO}_{2}$ evolution rate under different crops during an irrigation cycle in a mountain oasis of Oman, Appl. Soil Ecol., 25, 85-91, 2004.

Xiang, G., Weiping, H., Fengxue, G., and Rui, G.: The impact of rainfall on soil respiration in a rain-fed maize cropland, Acta Ecol. Sin., 32, 7883-7893, 2012.

Xiang, G., Gong, D., and Fengxue, G.: Inhibiting soil respiration and improving yield of spring maize in fields with plastic film mulching, T. Chinese Soc. Agr. Eng., 30, 62-70, 2014.

$\mathrm{Xu}$, L. and Baldocchi, D. D.: Seasonal variation in carbon dioxide exchange over a Mediterranean annual grassland in California, Agric. For. Meteorol., 123, 79-96, https://doi.org/10.1016/j.agrformet.2003.10.004, 2004.

$\mathrm{Xu}$, L., Baldocchi, D. D., and Tang, J.: How soil moisture, rain pulses, and growth alter the response of ecosystem respiration to temperature, Global Biogeochem. Cy., 18, 1-10, https://doi.org/10.1029/2004gb002281, 2004.

Yan, M., Zhou, G., and Zhang, X.: Effects of irrigation on the soil $\mathrm{CO}_{2}$ efflux from different poplar clone plantations in arid northwest China, Plant Soil, 375, 89-97, https://doi.org/10.1007/s11104-013-1944-1, 2014.

Yinkun, L., Minpeng, C., Xu, X., and Xurong, M.: Dynamics of soil respiration and carbon balance of summer-maize field under different nitrogen addition, Ecol. Environ. Sci., 22, 18-24, 2013.

Yu, Y., Zhao, C., Stahr, K., Zhao, X., Jia, H., and de Varennes, A.: Plastic mulching increased soil $\mathrm{CO}_{2}$ concentration and emissions from an oasis cotton field in Central Asia, Soil Use Manage., 32, 230-239, https://doi.org/10.1111/sum.12266, 2016.

Zhang, F., Zhang, W., Qi, J., and Li, F.-M.: A regional evaluation of plastic film mulching for improving crop yields on the Loess Plateau of China, Agric. For. Meteorol., 248, 458-468, https://doi.org/10.1016/j.agrformet.2017.10.030, 2018.

Zhang, Z., Tian, F., Zhong, R., and Hu, H.: Spatial and Temporal pattern of soil temperature in cotton field under mulched drip irrigation conditions in Xinjiang, T. CSAE, 27, 44-51, 2011.

Zhang, Z., Hu, H., Tian, F., Yao, X., and Sivapalan, M.: Groundwater dynamics under water-saving irrigation and implications for sustainable water management in an oasis: Tarim River basin of western China, Hydrol. Earth Syst. Sci., 18, 3951-3967, https://doi.org/10.5194/hess-18-3951-2014, 2014. 